Review

Naiming Lin*, Ruizhen Xie*, Jiaojuan Zou, Jianfeng Qin, Yating Wang, Shuo Yuan, Dali Li, Lulu Zhao, Luxia Zhang, Zhenxia Wang, Yong Ma, Pengju Han, Wei Tian, Xiaoping Liu, Zhihua Wang, and Bin Tang

\title{
Surface damage mitigation of titanium and its alloys via thermal oxidation: A brief review
}

https://doi.org/10.1515/rams-2019-0012

Received May 28, 2018; accepted Oct 04, 2018

\begin{abstract}
Titanium (Ti) and its alloys have been extensively applied in various fields of chemical industry, marine, aerospace and biomedical devices because of a specific combination of properties such as high strength to weight ratio, exceptional corrosion resistance and excellent biocompatibility. However, friction and wear, corrosion which usually occur on the surfaces of Ti-base components can lead to degradation in both properties and performance. Thermal oxidation (TO) of titanium and its alloys under certain conditions can accomplish significant improvements both in wear resistance and corrosion resistance, without special requirements for substrate geometries. In this review, the studies and applications of TO process in surface damage mitigation titanium and its alloys were reviewed and summarized.
\end{abstract}

Keywords: Surface damage; titanium; titanium alloys; surface strengthening;thermal oxidation

\footnotetext{
${ }^{\star}$ Corresponding Author: Naiming Lin: Research Institute of Surface Engineering, Taiyuan University of Technology, Taiyuan, 030024, P. R. China; Shanxi Key Laboratory of Material Strength and Structure Impact, Taiyuan University of Technology, Taiyuan, 030024, P R China; Department of Chemical and Materials Engineering, University of Alberta, Edmonton, AB T6G 1H9, Canada; Email: lnmlz33@126.com

*Corresponding Author: Ruizhen Xie: Department of Civil Engineering, Taiyuan University of Technology, Taiyuan, 030024, P R China

Jiaojuan Zou, Jianfeng Qin, Yating Wang, Shuo Yuan, Dali Li, Lulu Zhao, Luxia Zhang, Zhenxia Wang, Yong Ma, Xiaoping Liu, Bin Tang: Research Institute of Surface Engineering, Taiyuan University of Technology, Taiyuan, 030024, P. R. China

Pengju Han: Shanxi Key Laboratory of Material Strength and Structure Impact, Taiyuan University of Technology, Taiyuan, 030024, P R China; Department of Civil Engineering, Taiyuan University of Technology, Taiyuan, 030024, P R China

Wei Tian: Research Institute of Surface Engineering, Taiyuan University of Technology, Taiyuan, 030024, P. R. China; China United Northwest Institute for Engineering \& Research, Xi'an, 710082, P. R. China
}

๑ Open Access. ๑ 2019 N. Lin et al., published by De Gruyter. (cc) BY License

\section{Introduction}

Titanium (Ti) used to be considered a rare metal in $1800 \mathrm{~s}$ [1]. According to statistics Ti had been turned out to be the ninth most abundant element on earth and the fourth most abundant metal in the following century $[2,3]$. Ti and its alloys obtained considerable development since the pure metal (Ti sponge) firstly became commercially available by Kroll process in the middle of 20th century [4]. $\mathrm{Ti}$ and its alloys initially made their names in aerospace and chemical industries due to their promising strengthto-weight ratios, high tensile strength and excellent corrosion resistance [4]. While widespread use of Ti-base metals were limited somewhat by cost at that time $[2,3]$. In nowadays, Ti and its alloys are one kind of the most important structural metallic materials in in various industrial fields. Due to their relatively low modulus, good fatigue strength, promising formability/machinability, anticorrosion property and exceptional biocompatibility, increasing usage has been found in automotive applications, chemical processing equipment, pulp and paper industry, marine vehicles, biomedical devices and sporting goods after wide technical investigations and estimations $[5,6]$.

Nevertheless, Ti and its alloys cannot meet all of the requirements during engineering service. The drawbacks of low surface hardness, high/unstable friction coefficient in sliding contacts against common bearing materials, severe adhesive wear and susceptibility to galling are harmful for the direct application of Ti-base materials. Insufficient wear resistance is a major technological problem threatening to limit the extensively application of $\mathrm{Ti}$ and its alloys as they are subjected to aggressive and harsh working conditions during operation [7-9]. Because of removing or minimizing materials degradation/failure is nowadays necessary by existing raw materials and energy shortage,

Zhihua Wang: Shanxi Key Laboratory of Material Strength and Structure Impact, Taiyuan University of Technology, Taiyuan, 030024, P R China 

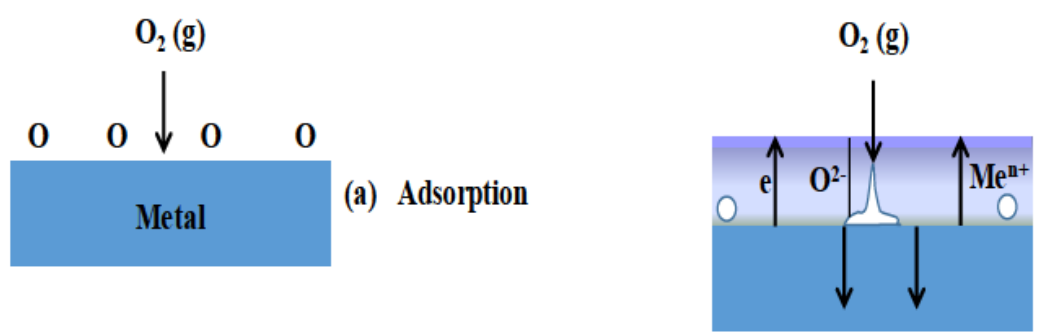

(d) Cavities, porosity, microcracks
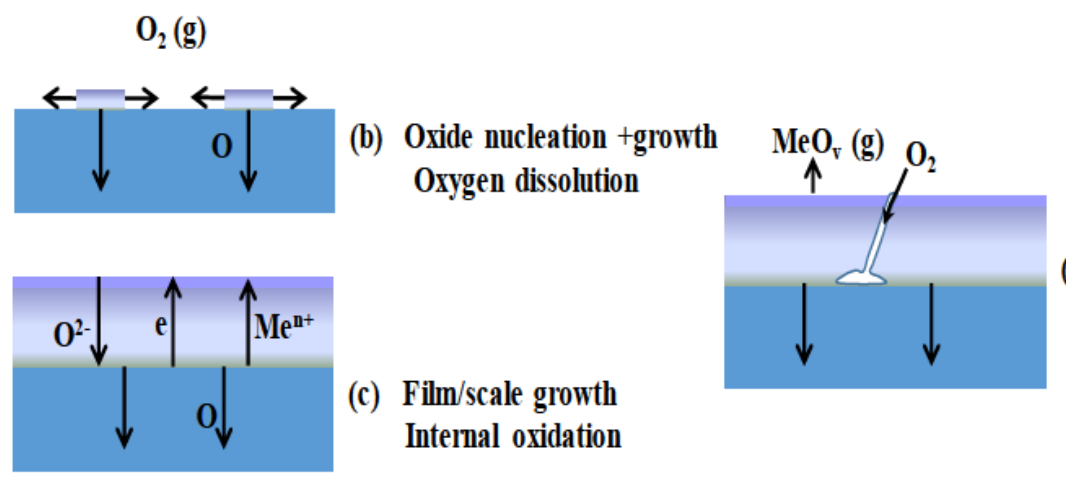

(e) Macrocracks, possible molten oxide, phases, oxide evaporation

Figure 1: High-temperature metal oxide formation diagram, (a) adsorption of oxygen, (b) diffusion of oxygen, (c) formation of film/scale, (d) growth of film/scale and (e) formation of thick oxide layer.

material scientists and engineers have long devoted themselves to design and produce new materials which are simultaneous with promising wear and corrosion resistance that can meet the increasing challenges and demands over wide range of modern industrial applications [10]. Another way of achieving this is utilizing appropriate surface treatment techniques, e.g. surface strengthening (deformation/phase transformation treatment), surface covering (coating/layer/film) and surface diffusion (thermochemical treatment or laser/plasma/electron beam alloying) on the surfaces of existing materials [1]. Surface treatments are able to realize a favorable compromise between the cost and the performance by endowing the material surfaces with high hardness value, effective frictionreduction, excellent corrosion resistance and promising mechanical performance, meanwhile the desirable bulk attributes of the materials are maintained [11].

A variety of surface treatment technologies, such as thermochemical surface treatment (nitriding, carburizing, surface alloying), micro arc oxidation (MAO)/plasma electrolytic oxidation (PEO), physical vapor deposition (PVD), chemical vapor deposition (CVD), ion implantation, thermal spraying, thermal oxidation (TO), laser surface treatment and electro-spark deposition (ESD), also several duplex treatments have been conducted to improve the surface performance of titanium and its alloys [12-25]. Among the existed surface treatment technologies, thermal oxidation (TO) which taking the advantage of high chemical affinity between $\mathrm{Ti}$ and oxygen (O), is an ideal surface technique that has been industrially used to strengthen the $\mathrm{Ti}$ and its alloys [26]. Its popularity is mainly assign to its cost effectiveness, simplicity and rapidity. Furthermore, the TO treatment has no special requirements for geometrical shapes of components [27]. TO process has been confirmed that it can afford combined improvements in wear resistance and corrosion resistance $[28,29]$. The benefits conferred by the TO process are attributed to both the formation of an external rutile oxide ceramic layer (inert/passivation capability) and an internal oxygen diffusion (solid solution strengthening) zone [30]. In this review, the technological principle was briefly introduced, surface damage mitigation of titanium and its alloys via TO treatment was presented and summarized. This work is expected to create database and provide reference information, thereby furtherly broaden the practical applications of TO treatment on titanium and its alloys.

\section{Thermal oxidation of titanium and its alloys}

A number of studies reported that a complete TO process of metals generally contains five steps (Figure 1) [2]: (1) absorption of oxygen, (2) dissolution of oxygen, (3) formation of thin oxide film, (4) growth of oxide layer, (5) formation of thick oxide layer. The oxidation reaction of Ti with oxygen 
is shown in Eq. (1):

$$
\mathrm{Ti}+\mathrm{O}_{2}=\mathrm{TiO}_{2}
$$

With respect of Ti alloys, taking Ti6Al4V as an example, other alloying elements will also react with oxygen as shown in the following Eqs. of (2) and (3):

$$
\begin{aligned}
\frac{4}{3} \mathrm{Al}+\mathrm{O}_{2} & =\frac{2}{3} \mathrm{Al}_{2} \mathrm{O}_{3} \\
\frac{4}{3} \mathrm{~V}+\mathrm{O}_{2} & =\frac{2}{3} \mathrm{~V}_{2} \mathrm{O}_{3}
\end{aligned}
$$

Under permanent temperature and pressure conditions, the standard Gibbs energy change $\left(\Delta G_{T}^{0}\right)$ can be obtained from the following equation [31]:

$$
\Delta G_{T}^{0}=\Delta H_{298}^{0}-T \Delta S_{298}^{0}+\int_{298}^{T} \Delta C_{p} d T-T \int_{298}^{T} \frac{\Delta C_{p}}{T} d T
$$

where $\Delta H_{298}^{0}$ is the standard free energy of formation at $298 \mathrm{~K}(\mathrm{~kJ} / \mathrm{mol})$, $\mathrm{T}$ the is temperature in Kelvin, $\Delta S_{298}^{0}$ is the standard absolute entropy at $298 \mathrm{~K}, \Delta C_{p}$ is the heat capacity. Eq. (4) can be furtherly simplified as follows:

$$
\Delta G_{T}^{0}=\Delta H_{298}^{0}-T \Delta S_{298}^{0}
$$

For all of the reactions, the values of $\Delta G_{T}^{0}$ belonging to $\mathrm{TiO}_{2}, \mathrm{Al}_{2} \mathrm{O}_{3}$ and $\mathrm{V}_{2} \mathrm{O}_{3}$ can be calculated according to Eq. (5). The values of $\Delta G_{T}^{0}$ can be applied to determine the feasibility of oxidation reactions and relative stability of oxides [31].

\subsection{Thermal oxidation of pure titanium}

Yan et al. [32] obtained a series of oxygen diffusion layers on commercially pure titanium by thermal oxidation. The TO procedures were conducted at $700^{\circ} \mathrm{C}$ for 1,2 and $4 \mathrm{~h}$, at $800^{\circ} \mathrm{C}$ and $900^{\circ} \mathrm{C}$ for $1 \mathrm{~h}$, respectively. The results showed that all the received TO layers consisted of a titanium oxide layer and an oxygen diffusion layer (containing an outer and an inner diffusion zone). It was seen that the higher the treatment temperature and the longer the holding time, the higher the oxygen concentration. XRD analysis revealed that with increasing $\mathrm{TO}$ temperature or soaking time, all the diffraction peaks corresponding to $\alpha$-Ti shifted to lower angles, indicating increased lattice parameters. The dissolved oxygen which induced the lattice distortion of $\alpha$-Ti had increased the $c / a$ ratio in the lattice, and consequently resulted in the improvement in hardness. Surface hardening effect of TO treatment on titanium was also able to enhance its wear resistance as expected.
Ye et al. [33] firstly processed the thermal oxidation treatment on commercially pure titanium (CP-Ti, TA2) at $500^{\circ} \mathrm{C}, 600^{\circ} \mathrm{C}, 650^{\circ} \mathrm{C}, 700^{\circ} \mathrm{C}, 750^{\circ} \mathrm{C}$ and $850^{\circ} \mathrm{C}$ for $210 \mathrm{~min}$. It was seen that the thermally oxidized samples revealed thicker $\mathrm{TiO}_{2}$ layers than the authigenic $\mathrm{TiO}_{2}$ layer on pure titanium, only as the TO temperature was above $600^{\circ} \mathrm{C}$. Meanwhile it was found that higher temperature benefited the thickening of $\mathrm{TiO}_{2}$ layer. All of the TO treated pure titanium presented improved corrosion resistance in $36 \%-38 \% \mathrm{HCl}$ at room temperature and in $30 \% \mathrm{H}_{2} \mathrm{O}_{2}$ at $36.5^{\circ} \mathrm{C}$. The most promising corrosion resistance was received when the TO treatment was conducted under $700^{\circ} \mathrm{C}$ for about 330-500 min.

Yan et al. [34] found that an oxide film composed of rutile $\mathrm{TiO}_{2}$ was formed on the surface of pure titanium after atmospheric thermal oxidation treatment $\left(600-900^{\circ} \mathrm{C} / 0.5\right.$ $24 \mathrm{~h}$ ). When the oxidation temperature is low and the time is short, the oxide film is well bonded to the substrate. With the increase of oxidation temperature and time, the binding force decreases. Between the oxide film and pure titanium is a layer of oxygen-permeating layer composed of an $\alpha$-phase Ti-O solid solution. With the increase of oxidation temperature and the prolongation of time, the oxygen content in the oxygen-permeating layer increases, and the thickness of the oxygen-permeable layer both inside and outside increases. The thickness of the oxygen-permeable layer is always slightly larger than that of the oxygenexpelling layer. In the early stage of oxidation, the growth of the oxygen-permeating layer and the oxide film follows the parabolic law. With the extension of the oxidation time, the growth of the oxide film was transformed into a straight line, and the change for growth of the oxygenpermeating layer is not obvious. When the oxidation time is short, the growth rate of the oxygen-permeable layer is greater than the growth rate of the oxide film. With the extension of the oxidation time, the growth rate of the oxide film exceeds the growth rate of the oxygen-permeable layer. The effect of temperature on the thickness of the oxygen barrier layer is greater than the effect of time.

In Aniołek et al's work [35, 36], the TO treatments were carried out under $500,600,700$ and $800^{\circ} \mathrm{C}$ for 20 and $40 \mathrm{~min}$, as well as 1, 2, 6, 24, 48 and $72 \mathrm{~h}$ on Grade 2 titanium. It was shown that temperature was the most important factor influencing the process of the formation of a TO layer on titanium, the oxidation kinetics of the tested materials at temperatures of 600,700 and $800^{\circ} \mathrm{C}$ followed the parabolic law. The results manifested that noticeably larger oxide particles were formed after oxidation at $600^{\circ} \mathrm{C}$, and raising temperature had resulted in the formation of finer and more agglomerated oxide particles, as received under $700^{\circ} \mathrm{C}$. Both of the TO layers obtained at 
a temperature of 600 and $700^{\circ} \mathrm{C}$ were composed of rutile $\mathrm{TiO}_{2}$ and $\mathrm{Ti}_{3} \mathrm{O}$. The formation of TO layer on titanium had enhanced its surface hardness, and also significantly improved the abrasive wear resistance. It was found that the TO process enabled the obtaining of TO layers featuring a 5 times higher hardness as compared with raw titanium. As the friction tests were performed against $\mathrm{Al}_{2} \mathrm{O}_{3}$ balls, the TO layers revealed no obvious friction-reduction effect on titanium, even an increase in their values were observed in the initial stage of friction tests. However, the wear volume values were decreased by $48 \%$ and $61 \%$ for titanium specimens subjected to TO treatment at 600 and $700^{\circ} \mathrm{C}$, respectively. The presence of a TO layer on the surface of titanium had significantly improved its resistance to abrasive wear.

Arslan et al. [37] investigated influence of surface roughness $(\mathrm{Ra})$ on corrosion and tribological behavior of CP-Ti after TO treatment. Firstly, CP-Ti specimens were polished with $\mathrm{SiC}$ abrasive papers to surface roughness values of $0.1,0.3$, and $0.6 \mu \mathrm{m}$. As the TO processes were conducted at $850^{\circ} \mathrm{C}$ for $8 \mathrm{~h}$ in an $\mathrm{O}_{2}$ atmosphere, the related TO treated specimens indicated increased surface roughness values of $\mathrm{Ra}=0.54,0.64$, and $0.7 \mu \mathrm{m}$. Single rutile $\mathrm{TiO}_{2}$ phase was formed on the CP-Ti surface after TO treatment. Furthermore it was seen that the surface roughness had no effect on the preferred growth orientation of the rutile phase. There was a diffusion zone formed by oxygen diffused beneath the oxide layer could be observed from a cross-sectional view. The TO layer indicated a surface hardness of $1097 \mathrm{HV}$, which was much higher than that of CP-Ti. As countered with WC- $6 \%$ Co balls, the CP-Ti specimens with surface roughness values of $\mathrm{Ra}=0.1,0.3$, and 0.6 , friction coefficients of $0.63,0.68$, and 0.74 were received, the TO treated specimens with surface roughness values of $\mathrm{Ra}=0.54,0.64$, and 0.7 had revealed friction coefficients of $0.48,0.53$, and 0.58 , respectively. Additionally, the wear morphologies of TO layers were smoother and displayed much less fluctuation as compared with that of the untreated CP-Ti. Macrorough surfaces usually have a relatively higher ion release rate and lower corrosion resistance than microrough surfaces, therefore the increase in the numbers of stable pits with increased surface roughness on the surface had resulted in negative corrosion potential and high corrosion current values for all samples. Generally the tribological and corrosion behavior of CP-Ti was improved by the TO layer formed by thermal oxidation. The decreased roughness showed promisingly improved the tribological and corrosion properties.

Bailey et al. [38, 39] conducted TO processes on CPTi at $625^{\circ} \mathrm{C}$ for 5,20 and $72 \mathrm{~h}$ and was with furnace cooling, respectively. By employ of glow discharge spectrom- etry (GDS) composition profile measurements and X-ray diffraction analysis, it was confirmed that the obtained TO layer showed a multi-layered structure on the CP-Ti: a titanium dioxide zone (rutile $\left.\mathrm{TiO}_{2}\right)+$ an $\alpha$-titanium oxygen diffusion zone (ODZ, $\alpha-\operatorname{Ti}(0))$. A extended treating time was able to bring out a thicker ODZ and made the $\alpha$-Ti(O) peaks more predominant in the entire TO layer. It was found that both the rutile $\mathrm{TiO}_{2}$ zone and ODZ had enhanced the anticorrosion property of CP-Ti indicating by decreased anodic currents and increased corrosion potential in $0.9 \%$ $\mathrm{NaCl}$ solution $(\mathrm{pH} \approx 7)$. Meanwhile the relatively high oxygen content in titanium lattice in the upper part of the ODZ could play a positive role in accelerating the formation of passive film on the surface and thus to mitigate corrosion damage of CP-Ti. In the dry sliding friction and tribocorrosion ( $0.9 \% \mathrm{NaCl}$ solution) tests against alumina $\left(\mathrm{Al}_{2} \mathrm{O}_{3}\right.$, Grade25) balls, the TO layers with higher surface hardness than that of CP-Ti were also exhibited much better resistance to material removal under different friction conditions than that of CP-Ti. In addition, obviously positive effect on the tribological performance of the TO layer through using a prior surface mechanical attrition treatment (SMAT) or controlled slow cooling after TO was verified, respectively.

Çomaklı et al. [40] firstly prepared $\mathrm{TiO}_{2}$ films on CPTi via sol-gel process, dip coating technique, then the deposited $\mathrm{TiO}_{2}$ films were subject to calcination in the temperature range of $500-900^{\circ} \mathrm{C}$ with increment steps of $5^{\circ} / \mathrm{min}$ for $2 \mathrm{~h}$ in furnace. The thickness of the $\mathrm{TiO}_{2}$ films increased with the rising of calcination temperature. The phase identification results showed that the anatase peaks were obtained from the films when the samples were calcinated at $500^{\circ} \mathrm{C}$. The intensities of the anatase peaks were increased as the calcination temperature was elevated to $700^{\circ} \mathrm{C}$. After calcinating at $900^{\circ} \mathrm{C}$, nearly all the anatase phase had transformed to the rutile phase. Polarization and electrochemical impedance spectroscopy measurements indicated better corrosion resistance of $\mathrm{TiO}_{2}$ films than that of raw CP-Ti in simulated body fluid solution. Corrosion resistance of coated samples also improved with increasing of calcination temperature, and the corrosion resistance of the calcinated samples were ranked as the following sequence: $\mathrm{TiO}_{2}$ film- $500^{\circ} \mathrm{C}<\mathrm{TiO}_{2}$ film $-700^{\circ} \mathrm{C}$ $<\mathrm{TiO}_{2}$ film $-900^{\circ} \mathrm{C}$.

Dearnley et al. [41] found that when the CP-Ti was modified by $\mathrm{TO}$ at $625^{\circ} \mathrm{C}$ for $36 \mathrm{~h}$, an exterior layer of $\mathrm{TiO}_{2}$ (rutile) with a thickness of $0.8 \mu \mathrm{m}$ was formed on the surface. There was a hardened oxygen diffusion zone (ODZ) with a thickness of about $10 \mu \mathrm{m}$ beneath the $\mathrm{TiO}_{2}$ layer. The exterior $\mathrm{TiO}_{2}$ layer revealed much higher hardness of $\sim 800$ $\mathrm{HV}_{0.005}$ than those of the ODZ ranging from $\sim 200$ to 800 
$\mathrm{HV}_{0.005}$, and the highest hardness of the ODZ was close to the exterior $\mathrm{TiO}_{2}$ layer. The $\mathrm{TO}$ treatment retarded the corrosion-wear of CP-Ti in physiological saline under reciprocation sliding contact against $\alpha-\mathrm{Al}_{2} \mathrm{O}_{3}$ ball. The protective effect which was realized by solid solution hardening (wear resistance) and accelerating forming of passive film (corrosion resistance), was attributed to high oxygen content in the ODZ.

Güçlü et al. [42] studied the effect of cold working on the TO behaviors of Grade $2 \mathrm{CP}$-Ti. The TO treatments of the $23 \%, 35 \%$ and $50 \%$ cold worked samples were conducted at 600 and $650^{\circ} \mathrm{C}$ for 60 and $72 \mathrm{~h}$, respectively. The recrystallization activation energy of each cold worked CP-Ti was calculated as $64-88 \mathrm{~kJ} / \mathrm{mol}$. Meanwhile the formation activation energies of oxygen diffusion zones were calculated as $149-170 \mathrm{~kJ} / \mathrm{mol}$ for the examined cold work ratios. These results revealed that as a cold worked CP-Ti was subjected to TO treatment, improved hardness and wear resistance were achieved on its surface.

Jamesh et al. [43] found that by conducting TO on CPTi in air at $650^{\circ} \mathrm{C}$ for $48 \mathrm{~h}$ had led to the formation of an oxide layer with a thickness of about $20 \mu \mathrm{m}$ throughout the surface without any spallation or flaking. The predominant phases in the oxide layer were rutile-TiO ${ }_{2}$ and oxygendiffused Ti, which meant the TO layer was also composed of an external oxide zone and an internal oxygen diffusion zone. Electrochemical tests showed that thermally oxidized CP-Ti revealed better corrosion resistance than that of the raw $\mathrm{CP}$-Ti in both 0.1 and $4 \mathrm{M} \mathrm{HCl}$ and $\mathrm{HNO}_{3}$ solution. The improvement in corrosion resistance of CP-Ti lied in the excellent chemical stability and mechanical isolation action of the TO layer on its surface.

Jamesh et al. [44] also investigated effect of cooling conditions (furnace, air and water cooling) on the corrosion resistance of TO treated CP-Ti alloys that obtained at $650^{\circ} \mathrm{C}$ for $14 \mathrm{~h}$ and $850^{\circ} \mathrm{C}$ for $6 \mathrm{~h}$. XRD analysis revealed that the phases in the TO layers were consistent with other published work [36, 41]. It was obvious that cooling conditions had negligible effect on the phase constitution of the resultant TO layers. In respect of the TO treated samples at $650^{\circ} \mathrm{C}$, faster cooling did not induce spallation or flaking on the surface of TO layers, and then there was no deleterious effect on the corrosion resistance of TO CP-Ti at $650^{\circ} \mathrm{C}$ in the $0.9 \% \mathrm{NaCl}$ solution. However, surface integrity of the TO treated samples at $850^{\circ} \mathrm{C}$ was damaged by both the air and water cooling, spallation and flaking were evident on the surfaces of the related TO treated samples at $850^{\circ} \mathrm{C}$. Additionally, cracking and spallation were more severe on the water cooled samples than the air cooled samples. Defects of spallation and flaking were not observed on the surfaces of the furnace cooled TO treated samples at $850^{\circ} \mathrm{C}$.
Electrochemical tests showed that the faster cooling rate had no deleterious effect on the corrosion resistance of TO treated samples at $650^{\circ} \mathrm{C}$ for $14 \mathrm{~h}$ whereas the faster cooling rate has deleterious effect on the corrosion resistance of TO treated samples at $850^{\circ} \mathrm{C}$ for $6 \mathrm{~h}$ in the $0.9 \% \mathrm{NaCl}$ solution. A conclusion could be drawn that furnace cooling or even slower cooling should be adopted after TO treatment under applicable conditions.

Kumar et al. [45] used to compare the frettingcorrosion behaviors of CP-Ti, anodized (using an electrolyte solution of $1 \mathrm{M} \mathrm{H}_{3} \mathrm{PO}_{4}$ containing $0.3 \mathrm{wt} . \% \mathrm{HF}$ at $20 \mathrm{~V}$ for $60 \mathrm{~min}$ ) and TO treated CP-Ti (prepared at $650^{\circ} \mathrm{C}$ for $48 \mathrm{~h}$ in air atmosphere) in Ringer's solution based on the change in free corrosion potential (FCP) measured as a function of time. It was seen that both anodizing and TO treatments had improved the fretting-corrosion resistance of CP-Ti. TO treated CP-Ti with far higher thickness indicated superior surface performance to that of the anodized one.

TO temperature and soaking time are the two main factors that can influence the TO behavior of titanium. Kumar et al. [46-48] systematically studied the effects of TO temperature and soaking time on structures and performance of TO layers. 500,650 and $800^{\circ} \mathrm{C}$ for $24 \mathrm{~h}$, as well as $8,16,24$ and $48 \mathrm{~h}$ were selected as the related TO parameters. Based on the corrosion protective ability, the untreated and TO treated samples for $24 \mathrm{~h}$ can be ranked as follows: $\mathrm{CP} \mathrm{Ti}$ $\left(800^{\circ} \mathrm{C}\right)>\mathrm{CP} \mathrm{Ti}\left(650^{\circ} \mathrm{C}\right)>\mathrm{CP} \mathrm{Ti}\left(500^{\circ} \mathrm{C}\right)>$ untreated $\mathrm{CP}$ Ti. From point of view of the corrosion protection, the untreated and TO treated samples at can be ranked as follows: $($ TO $48 \mathrm{~h})>($ TO $16 \mathrm{~h})>($ TO $8 \mathrm{~h}) \approx($ TO $24 \mathrm{~h})>$ untreated CP Ti. Finally, an optimal parameter of TO at $650^{\circ} \mathrm{C}$ for $48 \mathrm{~h}$ was obtained.

Lubas et al. [49] obtained the oxygen-diffused grade 2 titanium samples by TO treatment in fluidized bed at $610^{\circ} \mathrm{C}$ and $640^{\circ} \mathrm{C}$ for 6,8 , and $12 \mathrm{~h}$. $\mathrm{A} \mathrm{TiO}_{2}$ rutile film on the surface and a concentration gradient oxygen-diffusion zone in the subsurface of each titanium sample were formed by the TO treatment under different temperatures and various times. The Raman spectroscopy results showed that the $\mathrm{TiO}_{2}$ films consisted of anatase and tutile, for the analyzed variants of heat treatment. Thermal treatment in a fluidized bed was favorable for preparing uniform oxide layers on the surfaces with good adhesion to titanium substrates, as well as improving the surface properties of titanium to meet the demands for biomedical applications.

Shankar [50] carried out thermal oxidation on CP-Ti at $650^{\circ} \mathrm{C}$ for $96 \mathrm{~h}$, and a protective thick rutile $\mathrm{TiO}_{2}$ oxide layer with nano-rod structure was fabricated on its surface. Compared to original CP-Ti, the TO treated CP-Ti exhibited better corrosion resistance in boiling nitric acid indicating 
by much lower corrosion rate. The improvement in corrosion resistance of CP-Ti after TO treatment was attributed to the excellent chemical stability and mechanical isolation effect of the TO layer. It was viable that using the TO treated titanium components as they were exposed to nitric acid medium in aqueous reprocessing plants.

Krishna et al. [51] carried out comparative studies on the effect of cooling condition on surface performance of TO treated Grade $2 \mathrm{CP}$-Ti. The TO processes were conducted at various temperatures of $600,650,700,750,800$ and $850^{\circ} \mathrm{C}$ for $5 \mathrm{~h}$. After the TO treatment, the TO-samples were allowed to cool either in the furnace itself (cooling rate $2-3^{\circ} / \mathrm{min}$ ) or outside the furnace in ambient air (cooling rate $20-30^{\circ} / \mathrm{min}$ ), respectively. Taking TO layers obtained at $850^{\circ} \mathrm{C}$ for $5 \mathrm{~h}$ by both air cooling and furnace cooling as examples, poor adhesion of the TO layer with substrate for the air cooling samples was seen from the cross-sectional observation. Fast cooling resulted in a large thermal stress arising from the high ratio of the coefficient of thermal expansion Ti and rutile. The furnace cooled sample showed promising adhesion between the TO layer and the substrate. Relatively low cooling rate obviously reduced the thermal stress induced during the cooling process and this was helpful to maintain the integrity of the thick layer with the substrate, which was the key factor in the production of a thick and adherent rutile layer. Meanwhile, the TO layer obtained at $850^{\circ} \mathrm{C}$ for $5 \mathrm{~h}$ by furnace cooling also revealed superior tribological properties in terms of the low wear rate and the mild wear mode involved during the sliding process, as compared with raw titanium.

Wang et al. [52] studied the acid-etched CP-Ti subjected to thermal oxidation at $450^{\circ} \mathrm{C}$ in an air ambient atmosphere for 2, 4 and $6 \mathrm{~h}$. The results showed that TO treatment slightly changed the nanoscale structure of titanium and improved the crystallinity of the titanium surface layer. Cells cultured on the three TO treated titanium surfaces grew well and presented better osteogenic activity than the original samples. The in vivo bone-implant contact also demonstrated improved osseointegration after several hours of TO. This TO treated titanium samples enhanced the osteogenic differentiation activity of rat bone marrow mesenchymal stem cells (rBMMSCs) and improved osseointegration in vivo, indicating that TO treatment could potentially be applied in clinical operations to enhance bone-implant integration.

In order to enhance the implant-bone interfacial bonding strength, Yamamoto et al. [53] firstly prepared poly(vinyl alcohol) (PVA) film on CP-Ti and then conducted TO treatment on the PVA coated CP-Ti at $700^{\circ} \mathrm{C}$ for $1 \mathrm{~h}$ in an ultra-pure argon atmosphere. It was showed that TO in a pure argon atmosphere of PVA coated titanium has been proved to be an effect process to induce the formation of an anatase $\mathrm{TiO}_{2}$ surface layer and an underlying oxygen diffusion zone (ODZ). It was proposed that the amorphous carbon layer evolved from PVA film which acted as an effective solid-state diffusion barrier, could retard oxygen diffusion through the inner anatase $\mathrm{TiO}_{2}$ layer and impede fast consolidation of the oxide layer. The TO treated titanium possessed a surface with good bioactivity, as demonstrated by the apatite precipitates formed after immersed in simulated body fluid (SBF) solution. The bioactivity or apatite formation ability was considered lied in the presence of the anatase $\mathrm{TiO}_{2}$ outermost surface layer and in abundant hydroxyl groups (-OH) formed on the ODTi surface during immersion in SBF.

\subsection{Thermal oxidation of Ti6Al4V titanium alloys}

Up to now, Ti6Al4V is still the most frequently and successfully applied titanium alloy which occupies about one half of the total world production of titanium alloys [1]. Great success has been achieved on Ti6Al4V after TO treatment with various parameters. The mechanism of improvements in surface hardness, tribological performance and corrosion resistance are similar to TO treated titanium.

In Biswas et al's [26] work, a series of TO layers were produced on Ti6Al4V at 400,500 and $600^{\circ} \mathrm{C}$ for 25,36 and $60 \mathrm{~h}$. It was evident that oxide peak intensities were very weak and comprised mainly anatase, a few rutile and $\mathrm{Ti}_{2} \mathrm{O}_{3}$ peaks, as the TO treatments were conducted at temperatures of 400 and $500^{\circ} \mathrm{C}$, regardless of various TO duration. It was also observed that $\alpha$-Ti peaks broadened at low angles, which were known to be the peaks of distorted $\mathrm{Ti}$, generated from the lattice expansion by oxygen dissolution. When the TO layers were received at $600^{\circ} \mathrm{C}$, the intensity of the distorted Ti peaks gradually decreased and the anatase and rutile peaks revealed more dominant with higher intensities. However, the rutile peaks were found to be more prominent with increase in temperature. Rutile phase with high performance was expected to obtain in the TO layer. After relevant measurements, it was showed that TO of Ti- $6 \mathrm{Al}-4 \mathrm{~V}$ at $600^{\circ} \mathrm{C}$ for $36 \mathrm{~h}$ offered a defect free oxide scale with improved hardness and wear resistance.

Ashrafizadeh et al. [27] carried out TO treatments on Ti6Al4V alloy at 500, 600, 700 and $800^{\circ} \mathrm{C}$ for 1 -h cycles in muffle furnace under air atmosphere. Corrosion evaluation indicated that short oxidation treatment brought out dense and crack free TO layer and could significantly improve the corrosion resistance of Ti6Al4V alloy. However high temperatures and long cycles decreased the corro- 
sion resistance. TO treatment at $600^{\circ} \mathrm{C}$ with short oxidation time and low cooling rate, were found to be the appropriate conditions for improving the corrosion behaviour of Ti-6Al-4V alloy.

With a purpose to improve the wear resistance of Ti6Al4V for biomedical application, Luo et al. [29] carried out thermal oxidation treatment at $700^{\circ} \mathrm{C}$ in a gas mixture of nitrogen with $40 \%$ oxygen by volume ratio for $2 \mathrm{~h}$. A rutile $\mathrm{TiO}_{2}$ film of approximate $5 \mu \mathrm{m}$ with hardness of 21.11 GPa was formed on it. The TO treated Ti6Al4V showed low friction coefficient and excellent wear resistance against $\mathrm{ZrO}_{2}$ ball under $25 \%$ bovine serum lubrication.

In Wang et al's work $[28,54,55]$, the influence of TO duration and temperature on microstructure and wear resistance of TO layers on Ti6Al4V were investigated. It was found that the formed oxide coating mainly included rutile $\mathrm{TiO}_{2}$ as well as a little alumina. The weight gain with respect to the oxidation duration obeyed the linear oxidation kinetics law. The growth of oxide grains was in inadequate growth state of incomplete scale coverage from 2nd to 4th hour duration, in normal growth state from 4th to 6th hour duration while in excessive growth state of oxide particle agglomeration and surface roughening from 6th to 8th (or more than 8th) hour duration. And isothermal TO treatment at $700^{\circ} \mathrm{C}$ for $4 \mathrm{~h}$ was an optimal parameter that could realize a good synthetic effect. TO treatment had enhanced the micro-hardness of Ti6Al4V from $327 \pm 23 \mathrm{HV}$ to $742 \pm 27 \mathrm{HV}$ by obtaining a $10 \mu \mathrm{m}$ thickness oxide coating mainly composed of rutile $\mathrm{TiO}_{2}$ and alumina. TO layer decreased the average COF of original Ti6Al4V sample from 0.452 to 0.413 in dry sliding while from 0.228 to 0.197 in $25 \%$ bovine serum lubrication against $\mathrm{ZrO}_{2}$ balls. Under dry sliding condition and in $25 \%$ bovine serum lubrication, the wear volumes of TO treated sample had decreased by $37.6 \%$ and by $70.7 \%$, as compared with the original sample.

$\mathrm{Du}$ et al. [56] investigated the circulating air oxidation behaviors of Ti6Al4V alloys in the range $650-850^{\circ} \mathrm{C}$. The results of continuous oxidation kinetics showed that the air oxidation of Ti6Al4V alloy followed a parabolic rate law at 650 and $700^{\circ} \mathrm{C}$ after a logarithmic transient period, whilst at 750 and $800^{\circ} \mathrm{C}$, linear-parabolic kinetics were dominated. At $850^{\circ} \mathrm{C}$, after $50 \mathrm{~h}$ linear-parabolic oxidation, the alloy followed a parabolic rate law. The number of $\mathrm{Al}_{2} \mathrm{O}_{3}$ layer (occupying external gas/oxide interface) and $\mathrm{TiO}_{2}$ layer (appearing at oxide/substrate interface) increased with exposure time and temperature.

In García-Alonso et al's [57] study, the influence of thermal oxidation treatments of Ti6Al4V at $500^{\circ} \mathrm{C}$ and $700^{\circ} \mathrm{C}$ for $1 \mathrm{~h}$ on in vitro corrosion behaviour and osteoblast response was estimated. The results revealed that TO treatments had slight impacts on the in vitro corrosion resis- tance in simulated human fluids and biocompatibility of Ti6Al4V. Meanwhile the TO layer obtained at $700^{\circ} \mathrm{C}$ indicated superior in vitro osteoblastic cell attachment to the TO layer that received at $500^{\circ} \mathrm{C}$. To enhance the osseointegration of Ti6Al4V implants, Bodelón et al. [58] carried out TO treatment on Ti6Al4V implants at $700^{\circ} \mathrm{C}$ for $1 \mathrm{~h}$. The results indicated that the oxidation treatment promoted the formation of an oxide scale altering the nanoroughness of surface and improved the early bone formation. Bone mineral density (BMD) and bone-to-implant contact (BIC) were both slightly increased by oxidation treatment after 30 days of implantation in healthy and osteoporotic rabbits in the implantation site.

Dong and Shi et al. [59, 60] found that TO treatment was an effective surface engineering technique for Ti6Al4V to improve the tribological performance of ultrahigh molecular weight polyethylene (UHMWPE). The surface oxide layer with high hardness was able to give rise to the high resistance against three-body abrasive wear, the surface oxide layer possessed good wettability was also favorable for water lubrication, meanwhile TO treatment induced surface oxide layer was mechanically supported by the diffusion zone beneath. All the mentioned factors above contributed to the unique favourable tribological compatibility of TO treated Ti6Al4V with UHMWPE.

Zhang et al. [61] fabricated several TO layers consisting of $\mathrm{TiO}_{2}$ and minor $\mathrm{Al}_{2} \mathrm{O}_{3}$ on $\mathrm{Ti} 6 \mathrm{Al} 4 \mathrm{~V}$ alloy at temperature of $700 \pm 10^{\circ} \mathrm{C}$ for $10-40 \mathrm{~h}$. It was seen that TO treatment had significantly increased the surface hardness $(\mathrm{H})$ and elastic modulus (E) and reduced the $\mathrm{E} / \mathrm{H}$ ratio of the Ti6Al4V, which revealed the treatment could enhance the wear resistance of Ti6Al4V. TO treatment after long time could definitely increase the thickness of the oxide layer with multiple layer characterization, however, it could also lead to a weak bonding or even detachment of TO layer with the substrate.

Yang et al. [62] conducted TO on Ti6Al4V alloy at $750^{\circ} \mathrm{C}$ for $8 \mathrm{~h}$ in vacuum. It was showed that TO treatment in vacuum could promote the diffusion of oxygen into the substrate, the surface presented a uniformly dimpled morphology, $\mathrm{TiO}$ and $\mathrm{Ti}_{3} \mathrm{Al}$ phases were found in the hardened layer. The microstructure of the TO layer obtained in vacuum was thicker, more uniform and compact than that of the normal TO layer. Meanwhile the hardness gradient of TO layer received in vacuum was smoother and indicated better wear resistance in comparison to the conventional TO layer.

By employ of TO treatment, Dong et al. [63] obtained TO-treated Ti6Al4V alloy under atmosphere containing about $80 \%$ oxygen and $20 \%$ nitrogen at $600^{\circ} \mathrm{C}$ for $65 \mathrm{~h}$. The TO layer was composed of a thin rutile oxide layer $(\sim 2 \mu \mathrm{m})$ 
and an oxygen diffusion zone beneath $(\sim 20 \mu \mathrm{m})$. It was found that the significantly reduced tendency to adhesive wear and the improved wettability were realized on the surface of Ti6Al4V alloy after certain TO treatment, which increased the effectiveness of lubrication, had contributed to the enhanced wear resistance of the TO-treated sample.

Barranco et al. [64, 65] firstly blasted Ti6Al4V surfaces with $\mathrm{Al}_{2} \mathrm{O}_{3}$ particles (coarse) or $\mathrm{SiO}_{2}$ and $\mathrm{ZrO}_{2}$ particles (fine), and then conducted TO treatment on the blasted surfaces at $700^{\circ} \mathrm{C}$ for $1 \mathrm{~h}$. In terms of oxide scales, a pine needle-like morphology (anatase $\mathrm{TiO}_{2}$ ) and globular morphology (rutile $\mathrm{TiO}_{2}$ ) were formed on the finely and coarsely blasted samples, respectively. After TO treatment, two kinds of blasted Ti6Al4V presented improved corrosion resistance in Hank's solution as compared with the as-received blasted Ti6Al4V samples. The $\mathrm{TO}$ treated $\mathrm{Al}_{2} \mathrm{O}_{3}$ blasted Ti6Al4V samples showed better corrosion resistance in comparison to the TO finely blasted samples. The formation of stable oxide scale had decreased the surface reactivity and led to a lower passive current and wider passivation region, reduced the susceptibility to pitting corrosion. Meanwhile, TO treatment which was carried out on a pre-blasted Ti6Al4V surface, was favorable for osseointegration and long-term interfacial bonding between the implant and bone.

Billi et al. [66] proceeded TO treatments on Ti6 Al4V alloy disks at $500^{\circ} \mathrm{C}$ and $700^{\circ} \mathrm{C}$ for $1 \mathrm{~h}$, respectively. Frettingcorrosion tests were conducted on TO treated Ti6Al4V disks against the cadaver bone pins in bovine serum medium. The results showed that the TO treated Ti6Al4V alloy disks demonstrated low electrochemical reactivity in bovine serum medium; specifically $\mathrm{TO}$ treatment at $700^{\circ} \mathrm{C}$ indicated that the rutile TO layer formed potentially improved the performance of Ti6Al4V in fretting-corrosion against bone.

Borgioli et al. [67] treated the Ti6Al4V alloy disks in air circulating furnace at $1173 \mathrm{~K}$ for $2 \mathrm{~h}$ at $10^{5} \mathrm{~Pa}$ and then quenched using compressed air to remove the poorly bonded part of the TO layer. The modified Ti6Al4V alloy surface was covered with a $\sim 35 \mu \mathrm{m}$ thick hardened layer and exhibited gradient hardness values, from $\sim 970$ $\mathrm{HK}_{0.025}$ to matrix values. The wear volumes of the TO treated samples were from $\sim 4$ to 6 times lower than those of untreated Ti6Al4V samples, and the obtained TO layer even indicated better wear resistance than the plasma nitrided Ti6Al4V alloys.

Guleryuz et al. [68-70] used to investigate the diffusion kinetics of oxygen into the Ti6Al4V alloy substrates at $600-800^{\circ} \mathrm{C}$ for $0.5-72 \mathrm{~h}$. TO treatments resulted in hard surface layers consisting of $\mathrm{TiO}_{2}$ layer and oxygen diffusion zone (ODZ) beneath it. Oxidation rate followed parabolic kinetics between 600 and $700^{\circ} \mathrm{C}$. Parabolic oxidation provided dense and adherent oxide layer on the substrate by maintaining an activation energy Q oxidation value of 276 $\mathrm{kJ} / \mathrm{mol}$. At $700^{\circ} \mathrm{C}$ parabolic oxidation was dominant up to $36 \mathrm{~h}$ of oxidation, and prolonged oxidation yielded linear oxidation kinetics. Diffusion of oxygen into the Ti6Al4V alloy substrate beyond the oxide layer obeyed parabolic kinetics between 600 and $800^{\circ} \mathrm{C}$ by giving an activation energy Q diffusion value of $202 \mathrm{~kJ} / \mathrm{mol}$. Nevertheless, growth of ODZ obeyed parabolic kinetics at temperature range between 600 and $800^{\circ} \mathrm{C}$. As the Ti6Al4V was treated at $600^{\circ} \mathrm{C}$ for $60 \mathrm{~h}$, its surface hardness was enhanced from 450 to $1300 \mathrm{HV}_{0.01}$, and revealed a significantly improved wear resistance indicating by no measurable wear track on the surface as compared with the original Ti6Al4V after dry sliding against $\mathrm{Al}_{2} \mathrm{O}_{3}$ balls. After TO treatment at $600^{\circ} \mathrm{C}$ for $60 \mathrm{~h}$, the treated Ti6Al4V also exhibited excellent corrosion resistance in $5 \mathrm{M} \mathrm{HCl}$ solution. Meanwhile the resistance to corrosion-wear of TO-treated Ti6 Al4V alloy was almost 24 times higher than that of raw Ti6Al4V alloy when the reciprocating wear tests were conducted in $0.9 \% \mathrm{NaCl}$ solution using $\mathrm{Al}_{2} \mathrm{O}_{3}$ counters.

Jamesh et al. [71] thermal oxidized the Ti6Al4V alloys in air at $650^{\circ} \mathrm{C}$ for $48 \mathrm{~h}$ and the corrosion behavours of the modified Ti6Al4V alloys in 0.1 and $4 \mathrm{M} \mathrm{HCl}$ and $\mathrm{HNO}_{3}$ medium were studied. A uniform oxide scale $(\sim 7$ $\mu \mathrm{m})$ mainly composed of phase of the rutile and oxygendiffused titanium was formed throughout the surface. After certain TO treatment, the surface hardness of Ti6Al4V alloy was improved from $324 \pm 8$ (the value of substrate) to $985 \pm 40 \mathrm{HV}_{0.25}$. And the TO treated Ti6Al4V alloys also demonstrated better corrosion resistance in both $\mathrm{HCl}$ and $\mathrm{HNO}_{3}$ solution than that of plain Ti6Al4V samples. The uniform surface coverage, compactness and thickness of the oxide layer had provided an effective barrier towards corrosion of the Ti6Al4V alloy as expected.

Kumar et al. [72] performed TO treatment on Ti6Al4V alloy at 500, 650 and $800^{\circ} \mathrm{C}$ for $8,16,24$ and $48 \mathrm{~h}$ in air. It was seen that the surface morphology of TO treated Ti6Al4V alloy presented the formation of a thin adhered surface layer at $500^{\circ} \mathrm{C}$ that changed into a tiny grain structure at $650^{\circ} \mathrm{C}$ and a complete coverage of oxide islands with the grains oriented perpendicular to the substrate at $800^{\circ} \mathrm{C}$. The growth mode involved the formation of a thin oxide scale followed by its agglomeration and growth to completely cover the Ti6Al4V alloy surface. However, spalling of the oxide layer was found as the TO of Ti6Al4V alloys were performed at $800^{\circ} \mathrm{C}$ for 16 and $24 \mathrm{~h}$. When TO treatment was conducted at $650^{\circ} \mathrm{C}$ for $48 \mathrm{~h}$, it was showed a increased hardness by a factor of about 3 in comparison to the untreated alloy $\left(324 \pm 8 \mathrm{HV}_{0.2}\right)$. The corrosion resis- 
tance of untreated and thermally oxidized Ti6Al4V alloys was found to be ranked as follows: untreated Ti6Al4V $<\mathrm{TO}$ at $500^{\circ} \mathrm{C}$ for $8 \mathrm{~h}<\mathrm{TO}$ at $800^{\circ} \mathrm{C}$ for $8 \mathrm{~h}<\mathrm{TO}$ at $500^{\circ} \mathrm{C}$ for 24 $\mathrm{h}=\mathrm{TO}$ at $650^{\circ} \mathrm{C}$ for $8 \mathrm{~h}<\mathrm{TO}$ at $500^{\circ} \mathrm{C}$ for $16 \mathrm{~h}<\mathrm{TO}$ at $650^{\circ} \mathrm{C}$ for $48 \mathrm{~h}<\mathrm{TO}$ at $650^{\circ} \mathrm{C}$ for $16 \mathrm{~h}<\mathrm{TO}$ at $650^{\circ} \mathrm{C}$ for $24 \mathrm{~h}$. This ranking order revealed that the corrosion protective ability of thermally oxidized Ti6Al4V alloys did not follow a linear relation either with treatment temperature or time.

Li et al. [73] measured the normal spectral emissivity of the TO treated Ti6Al4V alloy and explored the possible reasons for the oscillatory behavior in emissivity during the TO process. It was found that prior to oxidation, the emissivity showed an approximately linear increasing between 823 and $973 \mathrm{~K}$. The emissivity increased gradually with the oxidation time as the sample was oxidized in air below $873 \mathrm{~K}$ and strong oscillations in emissivity were detected in transient oxidation period above $923 \mathrm{~K}$. The measurement results of surface composition, roughness and the film thickness revealed that variation in surface roughness was one of the factors influencing the amplitude of oscillation, and that the interference effect of the oxide film growth was the primary reason for the oscillatory behavior. The oxide film thickness, the roughness and the rate of oxidation were able to be estimated by using the theory of radiative effects of films. Above $923 \mathrm{~K}$, the growth process of oxide film followed the parabolic rule when the Ti6Al4V alloy was oxidized in air environment, and the oxidation rate was rapidly increased.

By conducting dynamic tests on thermally oxidized Ti6Al4V alloys using split Hopkinson pressure bar (SHPB), Niu et al. [74] found that the dynamic yield strength of Ti6Al4V alloys and the rate of strain hardening were enhanced after TO treatment. The increase in strain rate resulted in evident improved yield strength. The TO temperature had little effect on dynamic properties of Ti6Al4V alloy, but under different holding time for TO had greatly affected the initiation of plastic deformation and thus might potentially improve the ductility of the treated material. Thermal softening effect of the material resulted from higher testing temperature, also led to decrease in dynamic yield strength of Ti6Al4V alloys.

Poquillon et al. [75] carried out short TO treatments (stress relief thermal treatments) at $600-750^{\circ} \mathrm{C}$ on $\mathrm{Ti} 6 \mathrm{Al} 4 \mathrm{~V}$ alloys. Secondary ion mass spectroscopy (SIMS) analyses for the oxidation kinetics and oxygen diffusion in the matrix showed that mass measurements during thermal treatments showed that oxidation kinetics was parabolic and SIMS with rotating specimen had reduced the roughness and enhanced the precision of oxygen profile in the obtained TO layers.
With the aim to fabricate bio-inspired antibacterial nanotopography surfaces, nanospikes with varying dimensions were produced on Ti6Al4V alloy surfaces by Sjöström et al. [76] using TO technology in tube furnace at $800^{\circ} \mathrm{C}$ for $45 \mathrm{~min}$ with various Argon flow rates through the acetone bubbler $(50,100,200$ and $300 \mathrm{sccm})$. Then the received TO treated Ti6Al4V alloy were heated to $600^{\circ} \mathrm{C}$ at a rate of $10^{\circ} / \mathrm{min}$ to remove the carbon from the assynthesised nanospikes, which was able to grow vertically aligned nanospikes. The resultant oxide surface which showed nanospikes with approximately $20 \mathrm{~nm}$ diameters, was different from nanocolumn that obtained after common TO treatment. Microbiology studies using Escherichia coli. showed that the nanospikes on the Ti6Al4V alloy surfaces had potential to reduce bacterial viability. More dead bacteria were found on the nanospike surfaces compared to a smooth control. Finally a $40 \%$ reduction of viability was noted in bacterial suspensions incubated with a nanospike surface.

Tan et al. [77] fabricated titanium dioxide $\left(\mathrm{TiO}_{2}\right)$ nanowire surface structures on Ti6Al4V alloy by thermal oxidation process at $700^{\circ} \mathrm{C}$ for $8 \mathrm{~h}$ under Argon ambient and controlled flow rate. The nanowire surfaces exhibited better cell adhesion and spreading than the bare Ti6Al4V alloy, as well as presented higher cell proliferation. The $\mathrm{TiO}_{2}$ nanowire surfaces significantly improved the osteointegration of Ti6Al4V alloy, higher production levels of alkaline phosphatase (ALP), extracellular mineralization (ECM) and genes expression of runt-related transcription factor (Runx2), bone sialoprotein (BSP), ostoepontin (OPN) and osteocalcin(OCN) compared to the control Ti6Al4V surfaces.

Wang et al. [78] performed TO treatment under flowing water vapor atmosphere at $700^{\circ} \mathrm{C}$ for $4 \mathrm{~h}$ to modify the surface properties of Ti6Al4V. A $7.5 \mu \mathrm{m}$ thick hardened rutile $\mathrm{TiO}_{2}$ coating with hardness value increasing from 327 $\mathrm{HV}$ to $742 \mathrm{HV}$ were formed on Ti6Al4V alloy. The static contact angles for oxidized samples decreased with a reduction of $27.3 \%$ and $38.6 \%$ for distilled water and for $25 \%$ bovine serum, respectively. Under dry sliding condition, the coefficient of friction (COF) decreased $61.2 \%$ and wear volumes decreased $49 \%$ for TO treated Ti6Al4V in comparison to the bare samples. In respect of distilled water lubrication, the COF reduced $46.4 \%$ while wear volumes decreased $47 \%$ for TO-Ti6Al4V as compared with the raw Ti6Al4V. With respect to $25 \%$ bovine serum lubrication, the COF and wear volumes of TO treated samples had decreased $77.6 \%$ and $68 \%$ as compared with the untreated specimen. TO treated samples exhibited higher corrosion potential (Ecorr) and lower corrosion density (Icorr) values than those of the untreated $\mathrm{Ti6} \mathrm{Al} 4 \mathrm{~V}$ in distilled water 
and $25 \%$ bovine serum, which indicated an improvement of corrosion resistance after TO treatment.

Yazdanian et al. [79] performed a thermal oxidation process on Ti6Al4V alloy at $873 \mathrm{~K}$ for $60 \mathrm{~h}$ to improve its tribological properties. TO treatment had increased the surface hardness of Ti6Al4V alloy to $1631 \pm 240 \mathrm{KH}$. The protective effects of TO layer on Ti6Al4V were different as the wearing tests were conducted in vacuum and air atmosphere. The function of the TO layer on Ti6Al4V tested in vacuum was to prevent surface plastic deformation induced wear. In air testing condition, the TO layer worked as a barrier to protect Ti6Al4V surfaces from sliding-induced oxidative wear.

Lin et al. [80] focused on improving the surface performance of Ti6Al4V alloy used as petroleum tubes for oil and gas exploitation applications. TO process was applied to fabricate a TO layer on the Ti6Al4V substrate at $700^{\circ} \mathrm{C}$ for $30 \mathrm{~h}$. The results showed that the obtained TO layer was mainly composed of rutile phase $\mathrm{TiO}_{2}$ and minor anatase phase $\mathrm{TiO}_{2}$. The continuous and compact TO layer reached a total thickness of about $20 \mu \mathrm{m}$. The TO layer also contained an external oxide-layer and an internal O-diffusion layer. The TO layer showed enhanced hardness and good bonding strength indicating by scratch and indentation tests. Compared to the Ti6Al4V alloy substrates, the TO layers revealed superior surface performance in the electrochemical corrosion, erosive-wear and corrosive-wear measurements.

Zhou et al. [81] conducted TO of Ti6Al4V alloy at $800^{\circ} \mathrm{C}$ for $1 \mathrm{~h}$ or $900^{\circ} \mathrm{C}$ for $15 \mathrm{~min}$, and then vacuum diffusion at $850^{\circ} \mathrm{C}$ for $20 \mathrm{~h}$ was processed. It was seen that titanium oxide formed on the surface after $\mathrm{TO}$ treatment, then $\mathrm{TiO}_{2}$ decomposed after vacuum diffusion. Meanwhile some $\mathrm{Al}_{3} \mathrm{Ti}$ was detected. The TO+vacuum diffusion treated Ti6Al4V alloys always revealed better wear resistance regardless of the given load or wearing temperature confirming by the lowest weight losses.

Zhang et al. [82] conducted systematical investigation on the effect of treatment condition on boost diffusion of $\mathrm{TO}$ treated Ti6Al4V alloys. Isothermal oxidation was carried out at $800-900^{\circ} \mathrm{C}$ for different durations ( $\left.<80 \mathrm{~min}\right)$ under static ambient atmosphere and followed with furnace cooling. Then the TO treated samples were subject to boost diffusion treatment in a vacuum furnace $\left(10^{-6}\right.$ to $10^{-7} \mathrm{Torr}$ ) at $750-900^{\circ} \mathrm{C}$ for varied times (>60 $\mathrm{min}$ ). It was found that dissociation of the oxide layer was induced by boost diffusion. After boost diffusion treatment, a quality hardened zone with thickness up to $300 \mu \mathrm{m}$ on the surface of Ti6Al4V could be obtained by carefully controlled oxidation and boost diffusion processes. It could be concluded that in terms of effectiveness and the $\alpha-\beta$ transfor- mation temperature, $850-900^{\circ} \mathrm{C}$ was preferred in the boost diffusion treatment. At relatively high temperature, prolonged oxidation duration could produce more oxides on the Ti6Al4V surface, which was favorable to get harder and deeper strengthen zone that benefited from boost diffusion. Meanwhile, a critical vacuum which was responsible for the dissociation during boost diffusion process was proved to be no less than $10^{-6}$ Torr.

Hou et al. [83] found that under different thermal oxidation conditions, the surface oxide layer on Ti6 $\mathrm{Al} 7 \mathrm{Nb}$ and Ti6Al4V alloys shows a certain growth rules and properties. Under the same conditions, the oxide layer formed on the surface of Ti6Al7 Nb is thinner, the density is better, and the bonding force with the substrate is stronger than that of Ti6Al4V. When the temperature is less than or equal to $800^{\circ} \mathrm{C}$, Ti6Al7Nb follows the parabolic oxidation kinetics, while the oxidation rate of $\mathrm{Ti} 6 \mathrm{Al} 4 \mathrm{~V}$ at $700^{\circ} \mathrm{C}$ for more than $36 \mathrm{~h}$ is dominated by the linear oxidation kinetics. After oxidation for $1 \mathrm{~h}$, the oxide scale on the surface of the two alloys was mainly composed of rutile $\mathrm{TiO}_{2}$. Among them, anatase $\mathrm{TiO}_{2}$ appeared on the surface of Ti6Al4V alloy at $600^{\circ} \mathrm{C}$, and $\mathrm{Al}_{2} \mathrm{O}_{3}$ phase appeared at $900^{\circ} \mathrm{C}$. When the two alloys were oxidized at $800^{\circ} \mathrm{C}$ for $24 \mathrm{~h}, \mathrm{Al}_{2} \mathrm{O}_{3}$ appeared in the oxide layer. With the increase of oxidation temperature and the prolongation of oxidation time, the oxide layers of the two alloys are composed of rutile $\mathrm{TiO}_{2}$ and $\mathrm{Al}_{2} \mathrm{O}_{3}$ two phases.

\subsection{Thermal oxidation of other titanium alloys}

By employ TO treatment, Aniołek et al. [84] modified Ti6Al7 Nb alloys in the temperature range from $500-800^{\circ} \mathrm{C}$, in various time periods between $20 \mathrm{~min}$ and $72 \mathrm{~h}$. Determined on the basis of the weight gain, it was found that TO treatments of Ti6Al7 $\mathrm{Nb}$ alloys at temperatures of 600 , 700 and $800^{\circ} \mathrm{C}$, followed the parabolic law, and the obtained oxidation activation energy value was $170 \mathrm{~kJ} / \mathrm{mol}$. $\mathrm{TO}$ at 700 and $800^{\circ} \mathrm{C}$ for $72 \mathrm{~h}$ led to the formation of a compact crystalline layer of rutile $\mathrm{TiO}_{2}$ and a mixture of rutile and stable aluminium oxide $\alpha-\mathrm{Al}_{2} \mathrm{O}_{3}$. An addition of niobium at the amount of $7 \mathrm{wt} . \%$ had impeded the diffusion of oxygen in Ti6Al7 $\mathrm{Nb}$ alloy, and hence the TO process was delayed.

In addition, Feng et al. [85] formed a multi-layered scale on the Ti-Al-Si-N coating after oxidation at $800^{\circ} \mathrm{C}$ for $1000 \mathrm{~h}$, which consists of the top porous surface layer of $\mathrm{TiO}_{2}$, followed by a dense layer rich in $\mathrm{Al}_{2} \mathrm{O}_{3}$, a mixture oxides dense layer mainly composed of $\mathrm{TiO}_{2}, \mathrm{SiO}_{2}$ and some chromium oxide, and a bottom dense layer of chromium 
oxide was resulted from the selective oxidation of the substrate.

Wang et al. [86] discovered that Alloy C+, a modifying alloy $\mathrm{C}$ (Ti-35V-15Cr) by adding $0.6 \mathrm{Si}$ and $0.05 \mathrm{C}$, shows typical equiaxed $\beta$ grains with second phase precipitation and twin formation inside the $\beta$ grains in the as-rolled condition. Ageing treatment after solution and thermal exposure for a long period of time (exposure at $550^{\circ} \mathrm{C}$ for 100 hours) resulted in an increasing $\alpha$ phase precipitation at the grain boundaries due to their tendency for preferential nucleation of second phases.

Furtherly, Aniołek et al. [87] discovered that TO layer obtained at $600^{\circ} \mathrm{C}$ for $72 \mathrm{~h}$ on Ti6Al7Nb alloy consist of rutile and anatase $\mathrm{TiO}_{2}$ titanium oxides, and $\mathrm{NbO}$ niobium oxide. Based on nanoindentation tests, it was found that the TO layer indicated more than twofold higher hardness and higher modulus of elasticity in comparison to the original Ti6Al7Nb alloy. A significant enhancement in surface hardness and a reduction of $\mathrm{E}_{r} / \mathrm{H}$ ratio was considered to improve the resistance to abrasion wear of Ti6Al7Nb alloy. The scratch test results showed that the first damage of the TO layer was occurred at the load of $7.6 \mathrm{~N}$ and a total delamination was collected at the load of $65.9 \mathrm{~N}$.

Cimenoglu et al. [88] fabricated TO layer Ti6Al7 $\mathrm{Nb}$ alloy at $600^{\circ} \mathrm{C}$ for $60 \mathrm{~h}$ in air. The obtained TO layer was composed of a thin and relatively rough oxide layer with a thickness of $0.6 \mu \mathrm{m}\left(\mathrm{TiO}_{2}\right.$, rutile) and $5 \mu \mathrm{m}$ thick oxygen diffusion zone (ODZ) beneath the oxide layer. It was found that the TO layer with a relatively rough surface favored the deposition of hydroxyapatite ( $\mathrm{Ca}$ and P-rich) precipitates in the simulated body fluid (SBF) solution, and for anchoring of osteoblastic rat cells during cell culture tests as compared with the relatively smooth untreated surface. On the other hand, the used TO process revealed more than ten times enhancement in wear resistance in the SBF solution.

Omidbakhsh et al. [89] performed TO treatment on Ti-4Al-2V alloy at 450,600 and $650^{\circ} \mathrm{C}$ for $1-7 \mathrm{~h}$ in air atmosphere. Lattice parameters of the TO treated samples were calculated according to Cohen method for non-cubic systems. It was showed that lattice parameters of the asreceived alloy were calculated as $a=0.29289 \mathrm{~nm}$ and $c$ $=0.46652 \mathrm{~nm}$. Thermal oxidation results in a gradual increase in $a$-parameter at $450^{\circ} \mathrm{C}$ and maximum at higher temperatures $\left(600^{\circ} \mathrm{C}\right.$ and $\left.700^{\circ} \mathrm{C}\right)$, however $c$-parameter generally increased in the entire TO conditions. These changes might be due to the dissolution of oxygen atoms in the octahedral sites of the titanium hcp lattice.

Ebrahimi et al. [90] carried out the TO process on Ti$4 \mathrm{Al}-2 \mathrm{~V}$ alloy at $600^{\circ} \mathrm{C}$ and $750^{\circ} \mathrm{C}$ for $2 \mathrm{~h}$. It was found that TO treatment also resulted in the formation of an external $\mathrm{TiO}_{2}$ oxide layer and an internal oxygen diffusion zone (ODZ) on the surfaces of Ti-4Al-2V alloys. Prolonging TO time had given rise to the surface hardness values and hardening depth of TO treated samples. The results of rotary bending fatigue experiments indicated that TO process had significantly affected the fatigue crack initiation process, and fatigue limit of oxidized samples demonstrated a little increased at $600^{\circ} \mathrm{C}$ and then sharply decreased at $750^{\circ} \mathrm{C}$.

Gutiérrez et al. [91] conducted TO treatment on Ti-7 Nb6Al, Ti-13Nb-13Zr and Ti-15Zr-4Nb alloys in air at $750^{\circ} \mathrm{C}$ for $24 \mathrm{~h}$. In respect of Ti-13Nb-13Zr and Ti-15Zr-4Nb, their TO treated surfaces were mainly composed of $\mathrm{TiO}_{2}$, with smaller amounts of $\mathrm{Zr}$ and $\mathrm{Nb}$ oxides. While the treated $\mathrm{Ti}$ $7 \mathrm{Nb}-6 \mathrm{Al}$ showed a large increase of the $\mathrm{Al}$ concentration on the surface, and an absence of $\mathrm{Nb}$. The surface topography of thermal oxidized Ti-7Nb-6Al alloy was more regular and possessed a higher potentiality in biomedical application than that of Ti-Nb-Zr alloys.

Based on the results above, López et al. [92] modified Ti-6Al-7Nb, Ti-13Nb-13Zr and Ti-15Zr-4Nb by TO treatment in air at $750^{\circ} \mathrm{C}$ for $6-48 \mathrm{~h}$. The results revealed that the formed TO layers were tightly boned with the alloys. Under same oxidation time, Ti-6Al-7Nb alloy showed a thinner, more compact and dense TO layer than those of TiNbZr alloys, and the obtained oxide scales on the surfaces of three alloys presented similar properties. Additionally, Ti-6Al-7Nb alloy oxidized at $750^{\circ} \mathrm{C}$ during $48 \mathrm{~h}$ exhibited the lowest corrosion rates and the best pitting corrosion resistance.

Liu et al. [93] firstly fabricated Ti-5Al-5Mo-5V-1Cr-1Fe (TC18) alloy by laser melting deposition (LMD), and then conducted TO treatment on the LMD-TC18 alloy at $650^{\circ} \mathrm{C}$ under a gas mixture of oxygen (80\%) and nitrogen at a flow rate of $150 \mathrm{cc} / \mathrm{min}$ for $48 \mathrm{~h}$. A layer consisting of crystalline rutile $\mathrm{TiO}_{2}$ was produced on the LMD-TC18 alloy along with coarsening of $\alpha$ lath. The TO treated LMD-TC18 alloy alloy showed higher hardness and lower wear rate of the received LMD-TC18 alloy specimens. The promising sliding wear resistance of the TO treated LMD-TC18 alloy was ascribed to the existence of the lubricious rutile oxide layer and hardened oxygen diffusion zone (ODZ) on its surface.

Sado et al. [94] fabricated $\mathrm{TiO}_{2}$ layers with anatase phase on CP-Ti Ti-25Mo and Ti-25Nb alloys by two-step TO process. The first-step treatment was conducted in an Ar$1 \% \mathrm{CO}$ atmosphere at $1073 \mathrm{~K}$ for $3.6 \mathrm{ks}$, and the second-step treatment was conducted in air at $673-1073 \mathrm{~K}$ for $10.8 \mathrm{ks}$. It was found that the anatase phase was detected on the Ti-25Mo and Ti-25Nb alloys at higher second-step temperatures than on CP-Ti, which indicated that the incorporation of $\mathrm{Mo}$ and $\mathrm{Nb}$ into the $\mathrm{TiO}_{2}$ layer was effective for 
the suppression of the anatase-to-rutile transformation at high temperatures. While the $\mathrm{TiO}_{2}$ layers on the $\mathrm{Ti}-25 \mathrm{Nb}$ alloy exhibited excellent photocatalytic activity in the low anatase fraction region.

Ti-15Mo alloy has received considerable attention for biomedical applications thanks to its non-toxic nature, good mechanical properties and better corrosion resistance. Nithideth Somsanith et al. [95] conducted TO treatment on Ti-15Mo alloy at different temperatures for various periods $\left(500,650\right.$ and $800^{\circ} \mathrm{C}$ for $8,16,24$ and $48 \mathrm{~h}$ ). It was found that increasing the TO temperature from 500 to $650^{\circ} \mathrm{C}$ resulted in an increase in the growth rate and the oxide grain size of the oxide film, which made the oxide film relatively rougher than those prepared at $500^{\circ} \mathrm{C}$. An increase in the oxide grain size was also observed as the TO treatment time was prolonged from 8 to $24 \mathrm{~h}$ when treated at $500^{\circ} \mathrm{C}$, while an increased surface coverage and formation of many oxide nodules were observed at $650^{\circ} \mathrm{C}$ under similar conditions. TO treatment enhanced the average surface roughness (Ra) and microhardness, while decreased the water contact angle of the Ti-15Mo alloy. The phase contents of the oxide layer revealed a strong dependence on treatment conditions with a predominance of the rutile phase over the anatase phase at temperatures $>650^{\circ} \mathrm{C}$ and for time periods $>16 \mathrm{~h}$. Ti-15Mo alloys that subjected to TO showed more positive corrosion potential and a lower passivation density as compared with the untreated alloy. TO treated Ti-15Mo alloys obtained at $650^{\circ} \mathrm{C}$ for $8-48 \mathrm{~h}$ showed better corrosion resistance than that treated at $800^{\circ} \mathrm{C}$ for 8 $\mathrm{h}$ in Ringer's solution.

\subsection{TO-related duplex surface treatment of titanium and its alloys}

Wen et al. [96] applied surface mechanical attrition treatment (SMAT) combined with thermal oxidation to improve the tribological and biomedical properties of CP-Ti. The SMAT was conducted using $\mathrm{ZrO}_{2}$ balls with diameter of 8 $\mathrm{mm}$ at a vibration frequency of $50 \mathrm{~Hz} .700^{\circ} \mathrm{C}-1 \mathrm{~h}$ was selected as the TO parameter. It was seen that both duplex treated Ti and TO Ti had presented total $O$ diffusion depths of about $10 \mu \mathrm{m}$, however, the $\mathrm{O}$ concentration was higher in duplex treated Ti than that of TO Ti at the same depth, especially in the near surface area. The duplex treated $\mathrm{Ti}$ than that of TO Ti revealed better tribological property, corrosion resistance and biocompatibility (cell viability) than those of the bare CP-Ti, as expected. The duplex treated Ti demonstrated lower friction coefficients, wear volumes and corrosion density, possessed better combination performance in comparison to TO Ti. The higher hardness and tribological property of duplex treated Ti can be attributed to the higher $\mathrm{O}, \mathrm{C}$ and $\mathrm{N}$ concentration in the near surface layer. The higher $\mathrm{O}$ concentration also contributed to the rapid passivation of duplex treated $\mathrm{Ti}$, and resulted in higher corrosion resistance. The duplex treated Ti showed the highest cell adhesion and best biocompatibility were ascribed to its highest surface energy, well crystallinity of rutile layer with abundant $O$ on its surface.

In Li et al's work [97], a two-step treatment including surface rolling combined with thermal oxidation process was developed to improve the wear resistance of Ti6Al4V alloy. The rolling parameters were: a load of $700 \mathrm{~N}$, a spindle speed of 105 revolutions per minute (rpm) and an axial feed of $0.05 \mathrm{~mm} /$ revolution. The influences of various TO temperatures $\left(700,750,800\right.$ and $\left.850^{\circ} \mathrm{C}\right)$ on the microstructure and mechanical properties of surfacemodified layers of the samples before and after multipass surface rolling were investigated. It was found that there was also a oxide zone and oxygen diffusion zone on the surface the duplex treated Ti6Al4V, the duplex treated sample showed more compact internal structure and better properties on the surface than that of the single TO treated sample. There were no obvious difference in surface roughness and microhardness of the duplex treated and TO treated Ti6Al4V. However, all the duplex treated Ti6Al4V alloys revealed significantly improved friction-reduction effect, wear and corrosion resistance as compared to the TO treated Ti6Al4V. Meanwhile the duplex treated samples showed better wear and corrosion resistance compared in comparison to the untreated samples as the TO temperature increased.

Sun et al. [98] produced dimple surface texture (ST) with a diameter $(160 \pm 5 \mu \mathrm{m})$, a depth $(40 \pm 5 \mu \mathrm{m})$, a dimples densities (30\%) and an interval distance $(260 \mu \mathrm{m})$ on Ti6Al4V by laser surface texture (LST), and a thermal oxidation process was carried out on the untextured and textured samples under $500^{\circ} \mathrm{C}, 650^{\circ} \mathrm{C}$ and $800^{\circ} \mathrm{C}$ for $5-50 \mathrm{~h}$. The LST treated Ti6Al4V were well covered with uniform and continuous TO coatings. It was also found that ST could decrease the internal stress and effectively improve bonding strength of the oxide film to the Ti6Al4V substrate. Under dry friction conditions, the TO-LST Ti6Al4V revealed much lower wear rates compared to the original Ti6Al4V under the same applied loads against GCr15 steel and $\mathrm{ZrO}_{2}$ balls. The TO-LST Ti6Al4V surface received at $650^{\circ} \mathrm{C}$ for $25 \mathrm{~h}$ suggested the most excellent tribological properties, which was attributed to good comprehensive properties: a strongly bonded rutile coating with high hardness $(7.73 \mathrm{GPa})$, increased hardness to elastic modulus ratio (0.096) and improved load-bearing capacity. The TOLST Ti6Al4V obtained at optimal parameters with promis- 
ing surface performance could withstand or weakened the wearing damages, on the other hand, the ST was able to capture the wear debris and then decreased the abrasive wear. The TO+LST duplex treatment had indicated a satisfactory complementation on improving tribological behavior of Ti6Al4V.

Zhang et al. [99] conducted TO of CP-Ti and Ti6Al4V alloy with gold pre-deposition at high temperatures. It was seen that pre-deposited gold could promote the formation of a thicker oxide layer and more absorption of oxygen as compared with conventional thermal oxidation. Further investigations revealed that the existence of the thin gold layer was favorable for the outward diffusion of titanium during TO treatment. Catalytic role of gold seemed to change the oxidation mechanism by promoting the outward diffusion of titanium ions. Additionally gold was able to accelerate the formation of oxide layer on CP$\mathrm{Ti}$ and Ti6Al4V, however, the received oxide layers showed poor load-bearing capacity. Duplex treatment of gold predeposition + TO on CP-Ti and Ti6Al4V might be applied in some field where a special functional surface was required.

Vasylyev et al. [100] conducted ultrasonic impact treatment (UIT) on Ti6Al4V alloy in air at room temperature for 30-150 s, and realized an anomalously fast build-up of a relatively thick, dense and adherent amorphous oxide layer that composed of $\mathrm{TiO}_{2}, \mathrm{Al}_{2} \mathrm{O}_{3}$ and $\mathrm{V}_{2} \mathrm{O}_{3}$ with a small gradient of oxygen concentration across the layer. It was seen that the oxide layer thickness increased linearly with treatment time at a rate of $\sim 0.12 \mu \mathrm{m} \mathrm{s}^{-1}$, obtaining a maximum value of $12.3 \pm 3.2 \mu \mathrm{m}$ after UIT for 120 s. The mechanochemical oxidation of Ti6Al4V alloy was accompanied by the impact-induced incorporation of nitrogen and the formation of dispersed titanium nitride $\operatorname{TiN}_{x}$ and oxynitride $\operatorname{TiN}_{x} \mathrm{O}_{y}$ phases. In addition, the nitrogen atoms that penetrate deep into the alloy appear to form a nitrogen-rich or interstitial solid-solution-like $\alpha$ $\mathrm{Ti}(\mathrm{N})$ phase. Meanwhile impact treatment in the air was also coupled with the accumulation of the hardened steel needle component ( $\mathrm{Fe}, \mathrm{Cr}$ ) into the softer alloy, $\mathrm{Fe}_{2} \mathrm{TiO}_{4}$ was detected in the oxide layer. After UIT for 120s, the surface hardness of treated Ti6Al4V was increased about 1.1 times in comparison to the original sample. Additionally, the increase in hardness was accompanied by an enhancement in the tribological properties of the treated Ti6Al4V. It was showed that the treated Ti6Al4V revealed about 1.33 times lower friction than that for the base alloy, and indicated an increase in wear resistance by about $42 \%$.

\section{Summary}

Ti is the fourth most abundant structural metal in the world and is present in the earth's crust at a level of about 0.6 percent. Ti and its alloys have been rapidly developed since the pure metal first became commercially available about sixty years ago. Owing to their promising merits of high strength to weight ratio, high yield strength and toughness, good corrosion resistance as well as exceptional biocompatibility, Ti and titanium alloys have received an ever increasing interest in the fields ranging from civilian goods to military equipment. However, Ti and its alloys cannot meet all of the engineering requirements due to its demerits of low surface hardness values, high coefficient of friction and poor wear resistance, hence Ti and its alloy are seldom adopted as tribological-related engineering components. It has been well accepted that failure of material in engineering, e.g. wear or corrosion is mainly determined by the surface properties of the material rather than by bulk properties. Therefore the surface treatment is an attractive and suitable way to solve the aforementioned problems.

In order to improve the surface properties of titanium alloys, it is necessary to perform oxidation treatment at a suitable temperature. Studies have shown that thermal oxidation temperature and time have important effects on the thickness and density of the oxide layer. Usually the thickness of the oxide layer increases but the density decreases with the increasing temperature and time. When the temperature is low and the time is short, the thickness of the oxide layer is insufficient. If the temperature is too high, the oxide layer is not dense and the protection is poor. At the same time, it also affects the mechanical properties of the matrix. The time is too long and the effect of thickening the oxide layer is limited. The conventional oxidation research method needs to draw the oxidation kinetic curve by thermogravimetry, and the curve follows the parabolic, exponential, and cubic laws.

According to the literature, the wear resistance and corrosion resistance of Ti and its alloys had been remarkably enhanced to some extent after their surfaces were modified using thermal oxidation (TO). There is a high chemical affinity between Ti and oxygen, the obtained TO layer was formed by in-situ oxidation reaction under certain conditions. Promising and encouraging results showed that the improved surface performance of Ti and its alloys were due to surface hardness and surface composition had been changed. Meanwhile, the uniform and continuous TO layer had a strong bond with the substrate. The positive roles in wear and corrosion behaviors of the 
TO layer were attributed to its high hardness, promising bonding strength, good chemical stability and mechanical isolation action. The TO conditions of temperature, soaking time and cooling rate certainly had remarkable effect on the formation and performance of the TO layer. The TO layer produced by prolonged thermal oxidation at high temperatures (above $800^{\circ} \mathrm{C}$ ) or rapid cooling rate (faster than furnace cooling rate) can usually lead to de-bonding between the TO layer and the substrate. On the other hand, a TO layer fabricated at low temperatures and for short duration is too thin to use for practical applications. Meanwhile other surface technologies, such as surface deposition, surface severe plastic deformation and surface texturing hold their respective advantages in practical applications, duplex treatment of TO treatment combining with other surface processing technologies are expected to achieve more significant improvement in surface performance than that of the contributions of each technology acting separately. In summary, thermal oxidation is a simple, effective and environmental friendly method to modify the surfaces of titanium and its alloys for better property and performance, and achieve surface damage mitigation during service.

Acknowledgement: This work was supported by the National Natural Science Foundation of China (No.51501125 and No. 51474154), the China Postdoctoral Science Foundation (No.2012M520604 and No. 2016M591415), the Natural Science Foundation for Young Scientists of Shanxi Province (No.2013021013-2 and No.2014011015-7), the Youth Foundation of Taiyuan University of Technology (No.2012L050 and No.2013T011), the Qualified Personnel Foundation of Taiyuan University of Technology (No. tyutrc201157a).

\section{References}

[1] X.Y. Liu, P.K. Chu, and C.X. Ding, Mater. Sci. Eng. R, 47 (2004) 49-121.

[2] P.A. Schweitzer, Fundamentals of Metallic Corrosion: Atmospheric and Media Corrosion of Metals Corrosion: Atmospheric and Media Corrosion of Metals, CRC Press, Taylor \& Francis Group, Boca Raton, (2006).

[3] P.A. Schweitzer, Metallic Materials Physical, Mechanical, and Corrosion Properties, Marcel Dekker, Inc., Boca Raton, (2003).

[4] C. Leyens and M. Peters, Titanium and Titanium Alloys. Fundamentals and Applications, WILEY-VCH, Weinheim, (2003).

[5] S. Yuan, N.M. Lin, J.J. Zou, Z.Q. Liu, Z.X. Wang, L.H. Tian, et al., Surf. Coat. Technol., 368 (2019) 97-109.

[6] V.N. Moiseyev, Titanium Alloys: Russian Aircraft and Aerospace Applications, CRC Press Taylor \& Francis Group, Boca Raton,
(2006).

[7] M. Manjaiah and S.N. Basavarajappa, Rev. Adv. Mater. Sci., 36 (2014) 89-11.

[8] C. Veiga, J.P. Davim, and A.J.R. Loureiro, Rev. Adv. Mater. Sci., 32 (2012) 133-148.

[9] M. Łępicka and M. Grądzka-Dahlke, Rev. Adv. Mater. Sci., 46 (2016) 86-103.

[10] C. Veiga, J.P. Davim, and A.J.R. Loureiro, Rev. Adv. Mater. Sci., 34 (2013) 148-164.

[11] W.P. Liang, Q. Miao, F. Ying, P.Z. Zhang, and Z.J. Yao, Rev. Adv. Mater. Sci., 33 (2013) 106-110.

[12] M.R. Ripoll, R. Simič, J. Brenner, and B. Podgornik, Tribol. Lett., 51 (2013) 261-271.

[13] Ç. Albayrak, İ. Hacısalihoğlu, S.Y. Vangölü, and A. Alsaran, Wear, 302 (2013) 1642-1648

[14] K. Chen, X.P. Liu, X.Z. Liu, T.X. Meng, Q. Guo, Z.X. Wang, et al., J. Wuhan Univ. Technol. Mater. Sci. Ed., 31 (2016) 1086-1092.

[15] J.G. Tang, D.X. Liu, X.H. Zhang, D.X. Du, and S.M. Yu, Materials, 9 (2016) 217

[16] C.B. Tang, D.X. Liu, Z. Wang, and Y. Gao, Appl. Surf. Sci., 257 (2011) 6364-6371.

[17] M. Das, V.K. Balla, D. Basu, I. Manna, T.S.S. Kumar, and A. Bandyopadhyay, Scripta Mater., 66 (2012) 578-583.

[18] W. Yan and X.X. Wang, J. Mater. Sci., 39 (2004) 5583-5585.

[19] E. Marcelli, M.L. Costantino, T. Villa, P. Bagnoli, R. Zannoli, I. Corazza, et al., J. Prosthet. Dent., 112 (2014) 1201-1211.

[20] T.R. Rautray, R. Narayanan, and K.H. Kim, Prog. Mater. Sci., 56 (2011) 1137-1177.

[21] L. Joska, J. Fojt, O. Mestek, L. Cvrcek, and V. Brezina, Surf. Coat. Technol., 206 (2012) 4899-4906.

[22] P. Trivedi, P. Gupta, S. Srivastava, R. Jayaganthan, R. Chandra, and P. Roy, Appl. Surf. Sci., 293 (2014) 143-150.

[23] S. Durdu and M. Usta, Ceram. Int., 40 (2014) 3627-3635.

[24] F. Muhaffel, G. Cempura, M. Menekse, A.C. Filemonowicz, N. Karaguler, and H. Cimenoglu, Surf. Coat. Technol., 307 (2016) 308-315.

[25] B.G. Mellor, Surface Coatings for Protection against Wear, Cambridge, England Woodhead Publishing Limited, London, (2006).

[26] A. Biswas and J. Dutta Majumdar, Mater. Charact., 60 (2009) 513-518.

[27] Ashrafizadeh and F. Ashrafizadeh, J. Alloys Compd., 480 (2009) 849-852.

[28] S. Wang, Z.H. Liao, Y.H. Liu, and W.Q. Liu, Mater. Chem. Phys., 159 (2015) 139-151.

[29] Y. Luo, W. Chen, M.C. Tian, and S.H. Teng, Tribol. Int., 89 (2015) 67-71.

[30] N.M. Lin, P. Zhou, Y.T. Wang, J.J. Zou, Y. Ma, Z.X. Wang, et al., Surf. Rev. Lett., 22 (2015) 1550033 (11 Pages).

[31] D.J. Young, High Temperature Oxidation and Corrosion of Metals, Elsevier, Amsterdam, Netherlands, Sydney, (2016).

[32] W. Yan and X.X. Wang, Rare Metal Mater. Eng., 34 (2005) 471.

[33] X.M. Ye, F. Sun, Y. Wang, J. Hu, and Q.B. Du, Titanium Ind. Prog., 31 (2014) 21-24.

[34] W. Yan, Structure and properties of surface hardened layers on thermally oxidized industrial pure titanium, Master thesis, Zhejiang University, Hangzhou, China (2004).

[35] K. Aniołek, M. Kupka, and A. Barylski, Wear, 356-357 (2016) 23 29.

[36] K. Aniołek, M. Kupka, A. Barylski, and G. Dercz, Appl. Surf. Sci., 357 (2015) 1419-1426. 
[37] E. Arslan, Y. Totik, E. Demirci, and A. Alsaran, J. Mater. Eng. Perform., 19 (2009) 428-433.

[38] R. Bailey and Y. Sun, Wear, 308 (2013) 61-70.

[39] R. Bailey and Y. Sun, J. Mater. Eng. Perform., 24 (2015) 1669-1678.

[40] O. Çomaklı, M. Yazıcı, T. Yetim, A.F. Yetim, and A. Çelik, Surf. Coat. Technol., 285 (2016) 298-303.

[41] P.A. Dearnley, K.L. Dahm, and H. Çimenoğlu, Wear, 256 (2004) 469-479.

[42] F.M. Güçlü, H. Çimenoğlu, and E.S. Kayalı, Mater. Sci. Eng. C, 26 (2006) 1367-1372.

[43] M. Jamesh, S. Kumar, and T.S.N.S. Narayanan, J. Mater. Eng. Perform., 21 (2012) 900-906.

[44] M. Jamesh, T.S.N.S. Narayanan, and P.K. Chu, Mater. Chem. Phys., 138 (2013) 565-572.

[45] S. Kumar, T.S.N.S. Narayanan, S.G.S. Raman, and S.K. Seshadri, Mater. Sci. Eng. C, 30 (2010) 921-927.

[46] S. Kumar, T.S.N.S. Narayanan, S.G.S. Raman, and S.K. Seshadri, Mater. Sci. Eng. C, 29 (2009) 1942-1949.

[47] S. Kumar, T.S.N.S. Narayanan, S.G.S. Raman, and S.K. Seshadri, Corros. Sci., 52 (2010) 711-721.

[48] S. Kumar, T.S.N.S. Narayanan, S.G.S. Raman, and S.K. Seshadri, Mater. Charact., 61 (2010) 589-597.

[49] M. Lubas, M. Sitarz, J.J. Jasinski, P. Jelen, L. Klita, P. Podsiad, et al., Spectrochim. Acta, Part A, 133 (2014) 883-886.

[50] A.R. Shankar, N.S. Karthiselva, and U.K. Mudali, Surf. Coat. Technol., 235 (2013) 45-53.

[51] D.S.R. Krishna, Y.L. Brama, and Y. Sun, Tribol. Int., 40 (2007) 329-334.

[52] G.F. Wang, J.H. Li, K.G. Lv, W.J. Zhang, X. Ding, G.Z. Yang, et al., Sci. Rep., 6 (2016) 31769-1-13.

[53] O. Yamamoto, K. Alvarez, T. Kikuchi, and M. Fukuda, Acta Biomater., 5 (2009) 3605-3615.

[54] S. Wang, Z.H. Liao, Y.H. Liu, and W.Q. Liu, Surf. Coat. Technol., 252 (2014) 64-73.

[55] S. Wang, Z.H. Liao, Y.H. Liu, and W.Q. Liu, Surf. Coat. Technol., 240 (2014) 470-477.

[56] H.L. Du, P.K. Datta, D.B. Lewis, and J.S. Burnell-Gray, Corros. Sci., 36 (1994) 631-642.

[57] M.C. García-Alonso, L. Saldaña, G. Vallés, J.L. González-Carrasco, J. González-Cabrero, M.E. Martínez, et al., Biomaterials, 24 (2003) 19-26.

[58] O.G. Bodelón, C. Clemente, M.A. Alobera, S. Aguado-Henche, M.L. Escudero, and M.C. García-Alonso, Int. J. Implant. Dent., 2 (2016) 18 (9 Pages).

[59] H. Dong, W.Shi, and T.Bell, Wear, 225-229 (1999) 146-153.

[60] W. Shi, H. Dong, and T. Bell, Mater. Sci. Eng. A, 291 (2000) 27-36.

[61] C.Y. Zhang, Z.L. Wang, Z.Q. Tian, and H. Yang, Mater. Heat. Treat., 38 (2009) 99-103.

[62] Yang and X.D. Peng, Trans. Mater. Heat Treat., 34 (2013) 173-176.

[63] H. Dong and T. Bell, Wear, 238 (2000) 131-137.

[64] V. Barranco, M.L. Escudero, and M.C. García-Alonso, Acta Biomater., 7 (2011) 2716-2725.

[65] V. Barranco, E. Onofre, M.L. Escudero, and M.C. García-Alonso, Surf. Coat. Technol., 204 (2010) 3783-3793.

[66] F. Billi, E.Onofre, E. Ebramzadeh, T. Palacios, M.L. Escudero, and M.C. Garcia-Alonso, Surf. Coat. Technol., 212 (2012) 134-144.

[67] F. Borgioli, E. Galvanetto, F. Iozzelli, and G. Pradelli, Mater. Lett., 59 (2005) 2159-2162.

[68] H. Guleryuz and H. Cimenoglu, Biomaterials, 25 (2004) 33253333.
[69] H. Guleryuz and H. Cimenoglu, Surf. Coat. Technol., 192 (2005) 164-170.

[70] H. Guleryuz and H. Cimenoglu, J. Alloys Compd., 472 (2009) 241246.

[71] M. Jamesh, S. Kumar, T.S.N.S. Narayanan, and P.K. Chu, Mater. Corros., 64 (2013) 902-907.

[72] S. Kumar, T.S.N.S. Narayanan, S.G.S. Raman, and S.K. Seshadri, Mater. Chem. Phys., 119 (2010) 337-346.

[73] L.F. Li, K. Yu, K.H. Zhang, and Y.F. Liu, Int. J. Heat Mass Transfer., 101 (2016) 699-706.

[74] X.Y. Niu, Y.J. Yu, L.H. Ma, and L.B. Chen, Appl. Phys. A., 122 (2016) 597.

[75] Poquillon, C. Armand, and J. Huez, Oxid. Met., 79 (2013) 249-259.

[76] T. Sjöström, A.H. Nobbs, and B. Su, Mater. Lett., 167 (2016) 22-26.

[77] A.W. Tan, R. Ismail, K.H. Chua, R. Ahmad, S.A. Akbar, and B. Pingguan-Murphy, Appl. Surf. Sci., 320 (2014) 161-170.

[78] S. Wang, Y.H. Liu, C.X. Zhang, Z.H. Liao, and W.Q. Liu, Tribol. Int., 79 (2014) 174-182.

[79] M.M. Yazdanian, A. Edrisy, and A.T. Alpas, Surf. Coat. Technol., 202 (2007) 1182-1188.

[80] N.M. Lin, Q. Liu, J.J. Zou, D.L. Li, S. Yuan, Z.H. Wang, et al., RSC Adv., 7 (2017) 13517-13535.

[81] Y. Zhou, S.Q. Wang, Q.Y. Zhang, and L. Wang, Iron Steel Vanadium Titanium, 35 (2014) 35-39.

[82] Z.X. Zhang, H.S. Dong, T. Bell, and B.S. Xu, J. Alloys Compd., 431 (2007) 93-99.

[83] M. Hou, An comparative investigation on the thermal oxidation of Ti6Al7Nb and Ti6Al4V medical titianium alloys, Master thesis, Zhejiang University, Hangzhou, China (2010).

[84] K. Aniołek, M. Kupka, M. Łuczuk, and A. Barylski, Vacuum, 114 (2015) 114-118.

[85] C.J. Feng, M.S. Li, L. Xin, S.L. Zhu, Z.S. Shao, Q. Zhao, et al., Surf. Coat. Technol., 232 (2013) 88-95.

[86] X.X. Wang, W.Q. Wang, and Y.Q. Zhang, Mater. Sci. Forum, 765 (2013) 506-510.

[87] K. Aniołek and M. Kupka, Mater. Chem. Phys., 171 (2016) 374-378.

[88] H. Cimenoglu, O. Meydanoglu, M. Baydogan, H. Bermek, P. Huner, and E.S. Kayali, Met. Mater. Int., 17 (2011) 765-770.

[89] F. Omidbakhsh and A.R. Ebrahimi, Rare Met., 35 (2015) 149-153.

[90] A.R. Ebrahimi, F. Zarei, and R.A. Khosroshahi, Surf. Coat. Technol., 203 (2008) 199-203.

[91] A. Gutiérrez, M.F. López, J.A. Jiménez, C. Morant, F. Paszti, and A. Climent, Surf. Interface Anal., 36 (2004) 977-980.

[92] M.F. López, J.A. Jiménez, and A. Gutiérrez, Electrochim. Acta, 48 (2003) 1395-1401.

[93] L. Liu, Y.J. Shangguan, H.Z. Li, H.B. Tang, and H.M. Wang, Appl. Phys. A, 122 (2016) 477.

[94] S. Sado, T. Ueda, K. Ueda, and T. Narushima, Appl. Surf. Sci., 357 (2015) 2198-2205.

[95] S. Nithideth, T.S.N.S. Narayanan, K. Yu-Kyoung, P. Il-Song, B. Tae-Sung, and L. Min-Ho, Appl. Surf. Sci., 356 (2015) 1117-1126.

[96] M. Wen, C.E. Wen, P. Hodgson, and Y.C. Li, Colloids Surf. B, 116 (2014) 658-665.

[97] G. Li, S. Qu, Z. Ren, and X. Li, Surf. Innov., 5 (2017) 232-242.

[98] Q.C. Sun, T.C. Hu, H.Z. Fan, Y.S. Zhang, and L.T. Hu, Tribol. Int., 94 (2016) 479-489.

[99] Z.X. Zhang, H. Dong, T. Bell, and B.S. Xu, Oxid. Met., 66 (2006) 91-106.

[100] M.A. Vasylyev, S.P. Chenakin, and L F. Yatsenko, Acta Mater., 103 (2016) 761-774. 